\title{
Fibroblast Growth Factor-1 Suppresses TGF- $\beta$-Mediated Myofibroblastic Differentiation of Rat Hepatic Stellate Cells
}

\author{
Eva Peterová, Lucie Podmolíková, Martina Řezáčová, Alena Mrkvicová*
}

\author{
Department of Medical Biochemistry, Charles University, Faculty of Medicine in Hradec Králové, Hradec Králové, Czech \\ Republic \\ * Corresponding author: Charles University, Faculty of Medicine in Hradec Králové, Šimkova 870, 50038 Hradec Králové, \\ Czech Republic; e-mail: mrkvicovaa@1fhk.cuni.cz
}

\begin{abstract}
Summary: Myofibroblast expansion is a critical event in the pathogenesis of liver fibrosis. The activation of hepatic stellate cells (HSC) to myofibroblast (MFB) results in the enhanced production of extracellular matrix (ECM). In this study, we explored the effect of acidic fibroblast growth factor (FGF-1) treatment on a transforming growth factor (TGF- $\beta 1$ ) induced MFB conversion. We used HSC-T6 cell line, which represents well-established model of activated HSC. These cells strongly expressed $\alpha$-smooth muscle actin ( $\alpha$-SMA) and fibronectin (FN-EDA) after stimulation with TGF- $\beta 1$, which is a stimulus for MFB differentiation and ECM production. FGF-1 reduced proteins expression to levels comparable with untreated cells. Mild repression of secreted gelatinases was seen in culture media after FGF-1 treatment. The exposure of cells to collagen gel leads to changes in cell morphology and in expression of MFB markers. Lack of $\alpha$-SMA in cells embedded to collagen gel was detected. When stimulated with TGF- $\beta 1$, the cells increased expression of FN-EDA, but not $\alpha$-SMA. Although the cells on plastic and in collagen gel show different properties, FGF-1 reduced expression of FN-EDA in both conditions. Disrupting TGF- $\beta 1$ signalling pathway represents a potential strategy for the treatment of fibrosis. We showed that FGF-1 could antagonize signals initiated by TGF- $\beta 1$.
\end{abstract}

Keywords: Myofibroblast; Hepatic stellate cells; Collagen type I; TGF- $\beta 1 ; F G F-1 ; \alpha-S M A$

\section{Introduction}

Hepatic fibrosis is characterized by the excessive deposition of extracellular matrix (ECM). Liver fibrosis was considered to be an irreversible process in the past. Currently it is regarded as a dynamic process arising due to a failure of the normal wound healing. Hepatic stellate cells (HSC), major effector cells, can be activated by many inflammatory cytokines and undergo a myofibroblastic differentiation. Activated HSC are called myofibroblast, because they express high levels of $\alpha$-smooth muscle actin ( $\alpha$-SMA) and display the ability to contract ECM. While quiescent HSC cells do not synthetize any ECM proteins $(3,13)$, the activation of MFB results in the enhanced production of ECM components, including collagen types I, III, IV, V, and VI, and fibronectin. This is established as the central event in the development of hepatic fibrosis.

Activated HSC produce wide spectrum of cytokines and respond to their presence via autocrine loop. Transforming growth factor $\beta 1$ (TGF- $\beta 1$ ) is a potent fibrotic factor responsible for the synthesis of the extracellular matrix. TGF- $\beta 1$ induces the $\alpha$-SMA expression in fibroblastic cells of various origins $(21,29,31)$. TGF- $\beta 1$ acts through the TGF- $\beta$ type I and type II receptors to activate intracellular mediators, such as Smad proteins, the p38 mitogen-activated protein kinase (MAPK), and the extracellular signal-regulated kinase pathway $(7,12)$. Related to this signalling pathway are also fibroblast growth factors (FGFs). FGFs consist of seven families. Basic fibroblast growth factor (FGF-2) and acidic fibroblast growth factor (FGF-1) were found to be widely expressed in tissues. FGFs act through four types of tyrosine kinases receptors (FGFR). A unique feature shared by all members of the FGF family is their strong affinity for the glycosaminoglycan heparin. Heparin is necessary for biological activity of FGF-1. Despite the name, little is known about the effect of FGF-1 on myofibroblast. Few studies suggest that FGF-1, unlike FGF-2, displays antifibrotic functions. FGF-1 has been found to downregulate collagen expression and antagonize profibrogenic effects of TGF- $\beta 1$. FGF-1 inhibits TGF- $\beta 1$ induced Smad2 phosphorylation $(24,27)$, but the mechanism has not been fully elucidated. Our previous study showed that FGF-1 alone decreases the expression of $\alpha$-SMA and increases the expression of fibronectin (EDA-FN) in fully activated myofibroblasts isolated from a healthy rat liver (22).

Present work aims to elucidate, whether FGF-1 treatment could result in a deactivation of myofibroblasts. Most of studies dealing with MFB have been conducted in the conventional monolayer culture. Three-dimensional collagen matrices are often used as a model to study cell behaviour 
in the tissue-like environment (9). We provided novel assessment of the effect of FGF-1 on HSC-T6 in collagen gel. The TGF- $\beta 1$ stimulated HSC-T6 cells (immortalised cells which exhibit the typical features of activated HSC) were treated by FGF-1 and evaluated. Our data indicate that FGF-1 could revert the myofibroblastic differentiation.

To evaluate the effect of FGF-1/H(FGF-1 stabilized with heparin), HSC-T6 cells were stimulated with TGF- $\beta 1$ for $24 \mathrm{~h}$, and then treated with $\mathrm{FGF}-1 / \mathrm{H}$ in persisting presence of TGF- $\beta 1$ for another $24 \mathrm{~h}$. Nontreated cells were used as a control group. We examined mRNA expression using qPCR. To validate these results we performed the Western blot analysis and the detection of cellular localization of corresponding proteins using immunocytochemistry.

\section{Methods}

\section{Cell cultivation}

HSC-T6, an immortalized rat hepatic stellate cell line (34), was kindly gifted from Prof. Weiskirchen, (Institut für Molekulare Pathobiochemie, RWTH Universitätsklinikum Aachen, Germany). HSC-T6 cell line has been known have all features of activated HSC (30). HSC-T6 were cultured in Dulbecco's modified Eagle medium (DMEM, SigmaAldrich, Prague, Czechia) containing 10\% fetal bovine serum (FBS) (PAA, Cölbe, Germany), 4 mM L-glutamine, $100 \mathrm{U} / \mathrm{mL}$ penicillin (Sigma-Aldrich). Cells were maintained at $37{ }^{\circ} \mathrm{C}$ in $5 \% \mathrm{CO}_{2}$. After incubation for $24 \mathrm{~h}$ in complete DMEM cells were stimulated in serum free medium (SFM) with TGF- $\beta 1(1 \mathrm{ng} / \mathrm{ml})$ for $24 \mathrm{~h}$. To evaluate effect of FGF-1 cells were treated with FGF-1 $(4 \mathrm{ng} / \mathrm{ml})$ stabilized with heparin $(10 \mathrm{ug} / \mathrm{ml})(\mathrm{FGF}-1 / \mathrm{H})$ alone or with TGF- $\beta 1$ ( $1 \mathrm{ng} / \mathrm{ml})$ for $24 \mathrm{~h}$. Control cells were maintained in SFM. FGF-1 and TGF- $\beta 1$ were obtained from Peprotech (Rocky Hill, USA), heparin from porcine intestinal mucosa was obtained from Sigma-Aldrich.

\section{Collagen gel}

Rat tail collagen type I was prepared as described in Peterova et al. 2016. The cells (60 thousands) were suspended in $2 \mathrm{ml}$ of mixture of sterile collagen solution with $4 \times$ DMEM in the ratio $3: 1(\mathrm{v} / \mathrm{v})$. The gels were allowed to polymerize in the $\mathrm{CO}_{2}$ incubator for 1 hour at $37^{\circ} \mathrm{C}$ in Petri $35 \mathrm{~mm}$ dishes. First layer was covered with the same volume of DMEM containing 20\% FBS and antibiotics. After incubation for $24 \mathrm{~h}$ in complete DMEM cells were stimulated in serum free medium (SFM) with TGF- $\beta 1$ and FGF-1/H as described elsewhere.

\section{$R N A$ isolation and quantitative reverse transcription polymerase chain reaction ( $q R T-P C R)$}

The cells on plastic were washed with phosphate-buffered saline (PBS), harvested and dissolved in RLT lysis buffer (Qiagen, RNeasy Mini kit). Total cellular RNA was extracted by RNeasy Mini kit according to manufacturer instructions (Qiagen, Hilde, Germany). Collagen gel was dissolved by Clostridium histolyticum collagenase NB 4G proved grade (Serva, Heidelberg, Germany). 1 ug of RNA was reverse transcribed using cDNA Reverse Transcription Kit and quantified with TaqMan Gene Expression Assays (TGF $\beta 1$ Rn00572010_m1, Acta1 Rn01426628_g1, Fndc3a Rn01465936_m1, Col1a2 Rn00584426_m1, MMP2 Rn01538171_m1, TIMP1 Rn00587558_m1) using 7500 Fast Real-Time PCR system (all obtained from Applied Biosystems, Prague, Czechia). The relative expression from four independent experiments performed in duplicates was normalized to $18 \mathrm{~s}$ expression.

\section{Western blot analysis}

The cells were harvested, suspended in PBS containing $4 \mathrm{mM}$ EDTA and washed 3 times. Collagen gels were dissolved. The proteins were extracted with Cell lysis buffer 10× (Cell Signaling Technology, Danvers, USA). Protein content was determined by Bicinchoninic Acid Protein Assay Kit (Sigma-Aldrich). Forty $\mu \mathrm{g}$ of protein were applied on Novex NuPAGE 4-12\% Bis-Tris gel (Invitrogen Life Technologies, Prague, Czechia) under nonreducing conditions. The proteins were transferred to $0.2 \mu \mathrm{m}$ Hybond nitrocellulose membrane (GE Healthcare, München, Germany). Staining with Ponceau S was used as a loading control. The membranes were incubated with antibodies to $\alpha$-SMA (1A4, Sigma-Aldrich), cellular fibronectin (IST-9, Santa Cruz Biotechnology, Santa Cruz, USA) or MMP-2 (H-76, Santa Cruz), TIMP-1 (Santa Cruz) at $4{ }^{\circ} \mathrm{C}$ overnight. The secondary antibodies were from Santa Cruz. Detection was done with Western Blotting Luminol Reagent (Santa Cruz). The blots were scanned, quantified by program QUANTITY ONE 4.6 (Bio-Rad Laboratories, Hercules, California) and normalized to the respective controls.

\section{Immunocytochemistry}

The cells were fixed in $98 \%$ ethanol for 10 minutes. They were permeabilized on ice in cold solution of $0.1 \%$ Triton X-100 in $0.1 \%$ sodium citrate for $5 \mathrm{~min}$. Nonspecific binding sites were blocked by $10 \%$ fetal calf serum in PBS for $30 \mathrm{~min}$. The cells were incubated with the primary antibody at $4{ }^{\circ} \mathrm{C}$ overnight. Anti- $\alpha$-smooth muscle actin ( $\alpha$-SMA) clone 1A4 (Sigma-Aldrich) was diluted 1:400. The secondary antibody was Polyclonal Goat Anti-mouse immunoglobulins/HRP (Dako, Glostrup, Denmark); it was diluted 1:100 and the cells were incubated in the dark for 1 hour. Nuclei were stained with 4',6-diamidino-2-phenylindole (DAPI, Sigma-Aldrich) for $2 \mathrm{~min}$. Unspecific mouse immunoglobulins served as negative controls. Cells were washed with PBS, mounted in Vectashield (Vector Laboratories, Burlingame, California) and studied under Nikon Eclipse fluorescent microscope. 


\section{Gelatin zymography}

Zymographic analysis was performed on conditioned media. The cells cultured on gels were released with trypsin and plated on plastic for 24 hours. The medium was collected and compared with the medium of trypsinized cells cultured previously on plastic only. Protein concentration in the media was adjusted to $1 \mathrm{mg} / \mathrm{ml}$. Ten microliter aliquots were electrophoresed in 8\% SDS-polyacrylamide gel containing $0.1 \%$ gelatin (Sigma-Aldrich). The gel was washed in $2.5 \%$ Triton $\mathrm{X}-100$ for $1 \mathrm{~h}$ and subsequently incubated for $15 \mathrm{~h}$ at $37^{\circ} \mathrm{C}$ in $50 \mathrm{mmol} / \mathrm{L}$ Tris- $\mathrm{HCl}$ buffer $\mathrm{pH} 7.4$ containing $15 \mathrm{mmol} / \mathrm{L}$ sodium chloride and $10 \mathrm{mmol} / \mathrm{L}$ calcium chloride. The gel was stained with Coomasie brillant blue and destained with $40 \%$ methanol and $10 \%$ acetic acid solution. Gelatinolytic bands were size-calibrated with a high molecular mass marker (Bio-Rad).

\section{Statistical analysis}

Results are presented as mean \pm SD. Statistical significance of differences between groups was tested with one-way ANOVA. Significant results are shown wit asterisk (* $\mathrm{P} \leq 0.05 ; * * \mathrm{P} \leq 0.01)$. All calculations were performed using GraphPad Prism version 6.00 for Windows, GraphPad Software (San Diego, California USA).

\section{Results}

\section{TGF-ß1-induced myofibroblastic conversion is reversed by $\mathrm{FGF}-1 / \mathrm{H}$}

Figure 1 shows that stimulation of HSC-T6 with TGF- $\beta 1$ resulted in an increased mRNA expression of myofibroblast markers TGF- $\beta 1$ ( 3 fold) and $\alpha$-SMA (135 fold), but not that of fibronectin. Non-significant increase in an expression of collagen type I gene COL1A2 was observed. The addition of $\mathrm{FGF}-1 / \mathrm{H}$ decreased the mRNA expression of TGF- $\beta 1$ to similar levels that were observed in unstimulated cells. No effect of FGF-1/H on mRNA expression of fibronectin or COL1A2 was observed (Fig. 1A). On the protein level, however, $\alpha$-SMA and fibronectin protein amounts were changed during the treatment, as confirmed by Western blot and immunohistochemical analysis. Compared with TGF- $\beta 1$ treated cells, the addition of FGF-1/H led to a drastic decrease of fibronectin and $\alpha$-SMA protein levels, indicating a positive effect on the antimyofibroblastic conversion (Fig. 1B). Reduced $\alpha$-SMA expression after the FGF-1/H treatment (as visualized by immunofluorescence) supported these results. Upon stimulation or FGF1/H treatment the cells did not exhibit any morphological changes; proliferation was also unaffected (data not shown).

\section{Protective effect of collagen gel on FGF-1/H-induced reversal of myofibroblastic activation}

The importance of collagen environment on cell behaviour, phenotype and proliferation is widely accepted (10).
Cytokine induced myofibroblastic conversion and its reversal should be therefore confirmed under condition which could mimic in vivo fibrotic condition.

Figure 2 shows the effect of collagen gel cultivation on the expression of myofibroblastic markers during TGF- $\beta 1$ stimulation and FGF-1/H treatment. Cells were planted into the collagen type I gel. Collagen type I is almost not present in the space of Disse in a healthy liver. It becomes abundant during liver fibrosis progress due to HSC proliferation, activation and myofibroblastic conversion. When grown in collagen gel, HSC-T6 cell tend to clump together. Protrusions radiating from the outer margin of the clump are frequent (Fig. 2C). The cells in collagen gel responded to TGF- $\beta 1$ stimulus by an enhanced mRNA expression of $\alpha$-SMA (3fold). Addition of TGF- $\beta 1$ did not paracrinally stimulate TGF- $\beta 1$ gene expression, as seen on plastic. Also, no induction of COL1A2 or fibronectin genes was observed (Fig. 2A). Despite of the enhanced $\alpha$-SMA mRNA expression, we could not detect any changes at a protein level. More interesting is the fact that a control group of cells growing in the collagen gel had highly reduced levels of $\alpha$-SMA (non-detectable using immunofluorescence, Fig. 2C) compared to cells grown on plastic. FN-EDA was the only one of the tested markers that behaved in the same way in the cells cultivated on the plastic and in the collagen gel. An upregulation of FN-EDA protein expression after the TGF- $\beta 1$ treatment was detected; addition of FGF-1/H reduced it.

\section{FGF-1/H effect on the proteolytic phenotype of HSC-T6 on the plastic}

ECM remodelling is mostly carried out by the balance between activities of proteinases and their inhibitors. We tested cytokine mediated regulation of gelatinases MMP-2, MMP-9 and tissue inhibitors of MMP (TIMP-1, TIMP-2) on different substrates. Figure 3 shows the effect of TGF- $\beta 1$ cell stimulation and $\mathrm{FGF}-1 / \mathrm{H}$ treatment on amount of mRNA of MMP-2, MMP-9, TIMP-1, and TIMP-2 (Fig. 3A). Protein expressions of MMP-2 and TIMP-1 are also shown (Fig. 3B). TGF- $\beta 1$ stimulated the mRNA expressions of MMP-2, MMP-9 and TIMP-1 in HSC-T6. FGF-1/H attenuated the expression of TIMP-1 to levels comparable to those expressed by the untreated cells. Western blot showed that MMP-2 and TIMP-1 protein expression did not parallel the changes observed at the mRNA level. Neither the amount of the full-length $72 \mathrm{kDa}$ pro-MMP-2, nor the amount of fully active MMP-2 $62 \mathrm{kDa}$ form was changed after the TGF- $\beta 1$ cell stimulation or the FGF-1/H treatment. TGF- $\beta 1$ promotes a TIMP-1 protein expression that remained the same after the FGF-1/H treatment. Finally, enzyme activity of MMP2 and MMP-9 was measured by the gelatin zymography (Fig. 3C). Sample processing (involving de- and re-naturation) restores active form of the MMP, but also the gives the ability to digest gelatin to the normally inactive pro-MMPs. Gelatinolytic activities corresponding to the latent forms of MMP-2 and MMP-9 were present in conditioned media 


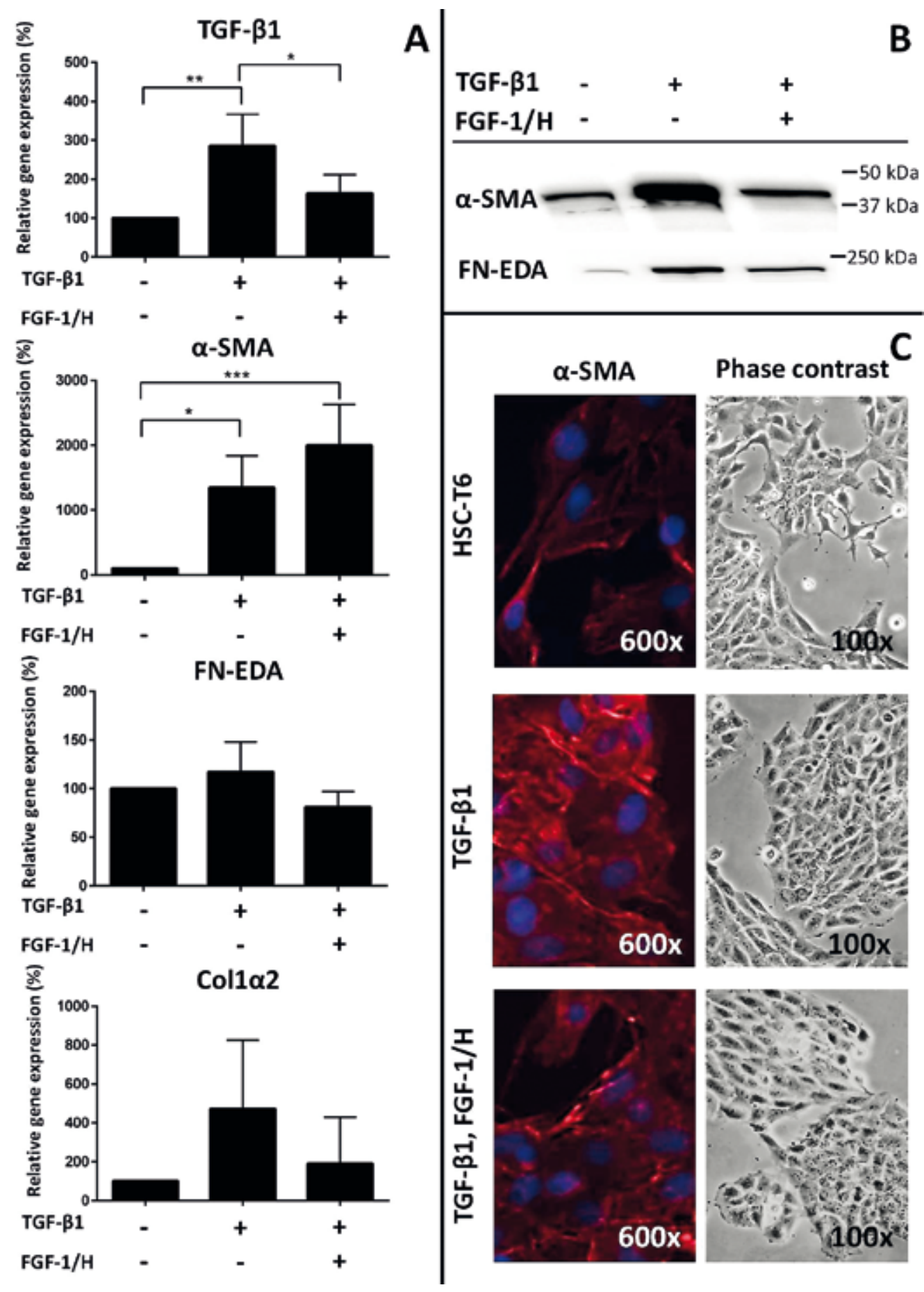

Fig. 1: Effect of FGF-1/H on the expression of myofibroblastic markers. Cells were treated with TGF- $\beta 1$ for $24 \mathrm{~h}$, then for another $24 \mathrm{~h}$ with FGF-1/H in combination with TGF- $\beta 1$ or TGF- $\beta 1$ alone. Stimulation of HSC-T6 with TGF- $\beta 1$ resulted in increased expression of TGF- $\beta 1$ and $\alpha$-SMA mRNA measured by qRT-PCR. Addition of FGF-1/H attenuated the expression of TGF- $\beta 1$. COL1A2 and fibronectin expression did not significantly respond to the treatment with FGF-1/H (A). Each bar represents mean \pm SD. Western blot for $\alpha$-SMA and fibronectin revealed increased expression of both proteins after TGF- $\beta 1$ stimulation., followed by decreased expression after FGF-1/H treatment (B). Four independent experiments were performed, statistical significance $* p \leq 0.05, * * p \leq 0.01$. Presence of $\alpha$-SMA (red) in HSC-T6 cell was detected by immunofluorescence (C). Nuclei were counterstained with DAPI (blue). Magnification (600×). Strong expression of $\alpha$-SMA was seen in the cells treated with TGF- $\beta 1$. Immunoreactivity was partially reduced after FGF-1/H treatment. The cells under phase contrast with lower magnification $(100 \times)$ are also presented (C right panel). 


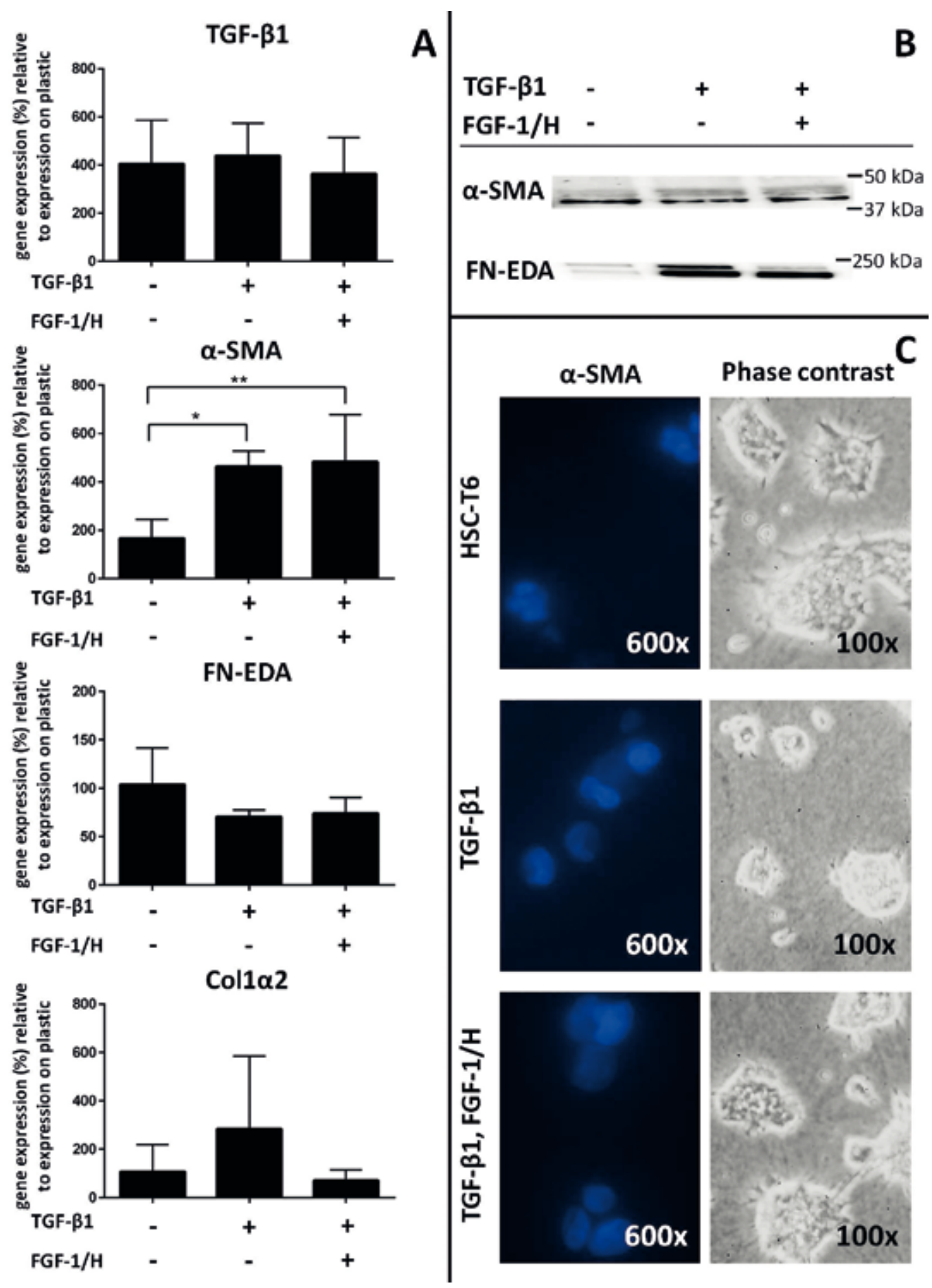

Fig. 2: Effect of collagen gel cultivation on FGF-1/H-induced myofibroblast deactivation. The cells were seeded in the three dimensional collagen gel and treated with TGF- $\beta 1$ for $24 \mathrm{~h}$, then for another $24 \mathrm{~h}$ with FGF-1/H in combination with TGF- $\beta 1$ or TGF- $\beta 1$ alone. Expression of markers of myofibroblastic conversion was measured using qRT-PCR Graphs (A) show the changes in mRNA expression levels with or without treatment (cells seeded on plastic dishes are set as 100\%). Each bar represents mean \pm SD. Four independent experiments were performed, statistical significance $* \mathrm{p} \leq 0.05,{ }^{* *} \mathrm{p} \leq 0.01$. Western blot for $\alpha$-SMA showed weak positivity in the cells in the collagen gel, no induction by TGF- $\beta 1$ treatment was seen. Fibronectin appeared after stimulation and the total protein levels drop after FGF-1 treatment (B). Neither unstimulated cells not stimulated or FGF-1 treated cells showed $\alpha$-SMA positivity as detected by immunofluorescence, only DAPI stained nuclei are visible (C). Cell under phase contrast are shown (C right panel). 

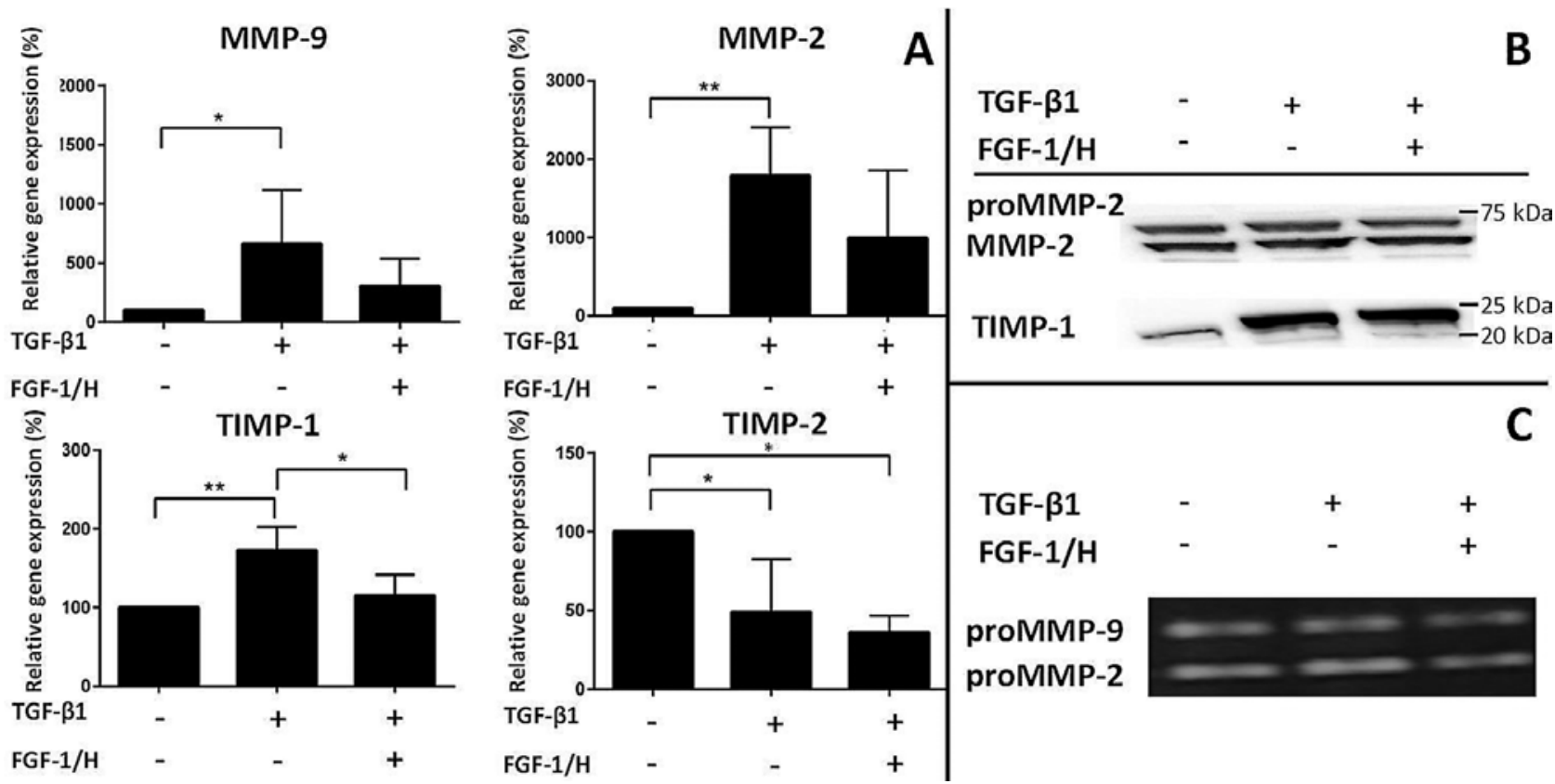

Fig. 3: Effect of FGF-1/H on the expression of gelatinases and MMP inhibitors. The cells were cultivated on plastic and treated with TGF-1 for $24 \mathrm{~h}$, then for another $24 \mathrm{~h}$ with FGF-1/H in combination with TGF- $\beta 1$ or TGF- $\beta 1$ alone. Stimulation of HSC-T6 with TGF- $\beta 1$ resulted in the increased expression of MMP-2, MMP-9 and TIMP-1 mRNA measured by qPCR. Addition of FGF-1/H attenuated the expression of MMP-2, MMP-9 and TIMP-1 (A). Each bar represents mean \pm SD. Four independent experiments were performed, statistical significance $* \mathrm{p} \leq 0.05, * * \mathrm{p} \leq 0.01$. In contrast, neither the TGF- $\beta 1$ stimulation nor the FGF-1/H treatment had any significant effect on the MMP-2 expression at a protein level (B). Expression of TIMP-1 protein increased after the TGF- $\beta 1$ stimulation. MMP-2 and MMP-9 activity was detected by a gelatin zymography. The FGF-1/H treatment mildly reduced pro-MMP-2 release into the culture media (C).

of HSC-T6. TGF- $\beta 1$ slightly induced pro-MMPs secretion, while $\mathrm{FGF}-1 / \mathrm{H}$ repressed it.

\section{FGF-1/H effect on the proteolytic phenotype of HSC-T6 in the collagen gel}

HSC-T6 cells were embedded in the collagen gel, followed by the cytokine stimulation. We found different expression patterns of the non-stimulated cells on the plastic and in the collagen gel. Graph 4 shows mRNA expressions of MMP-2, 9, and TIMP-1, 2 indicated as a percentage of the unstimulated control HSC-T6 seeded on plastic. Planting of the cells into the collagen gel alone dramatically increased MMP-2 expression. No effect of TGF- $\beta 1$ or FGF-1 on mRNA expression of genes of interest was observed. Western blot analysis revealed that TGF- $\beta 1$ induced expression of pro-MMP-2, however, most of it remained as a zymogen without being converted to the active form. In the collagen gel, the HSC-T6 cells secrete less MMP-2 and 9 in response to FGF-1 treatment.

\section{Discussion}

In the presented work, we demonstrate that FGF-1/H prevents TGF- $\beta 1$-induced myofibroblastic activation, as evi- denced by decreased levels of $\alpha$-SMA and FN-EDA. We also provide the evidence that MFB phenotypic switch is modulated by ECM. This finding is consistent with our previous work showing that FGF-1/H alone had a larger effect on MFB phenotype in the cells cultured on plastic than on those in collagen gel (22). In the previous study, fully activated MFB were generated by outgrowth of primary HSC, isolated from a normal rat liver. MFB and HSC differ in the ability to degrade $\mathrm{ECM}$ proteins. MFB represent a cell population with high collagenolytic potential (15), which HSC-T6 do not have. Thus the HSC-T6 cells can reflect an early phase of the liver damage, when cytokines play a crucial role in the activation of quiescent HSC.

The key cells participating in the development of the liver fibrosis are HSC and MFB. In the intact liver, HSC store retinoids and triacylglycerols in cytoplasmic lipid droplets. After a liver injury, HSC are activated into contractile MFB. Cytokines released from damaged hepatocytes and Kupfer cells are major stimulants (26). TGF- $\beta 1$ appears to be responsible for the stimulation of ECM proteins expression and inhibition of their degradation $(4,8)$. An important property of TGF- $\beta 1$ is the ability to induce its own mRNA expression, and thereby multiply its effect (32). TGF- $\beta 1$ induces mRNA expression of MFB markers, such as $\alpha$-SMA, procollagen, and fibronectin (17). It was 


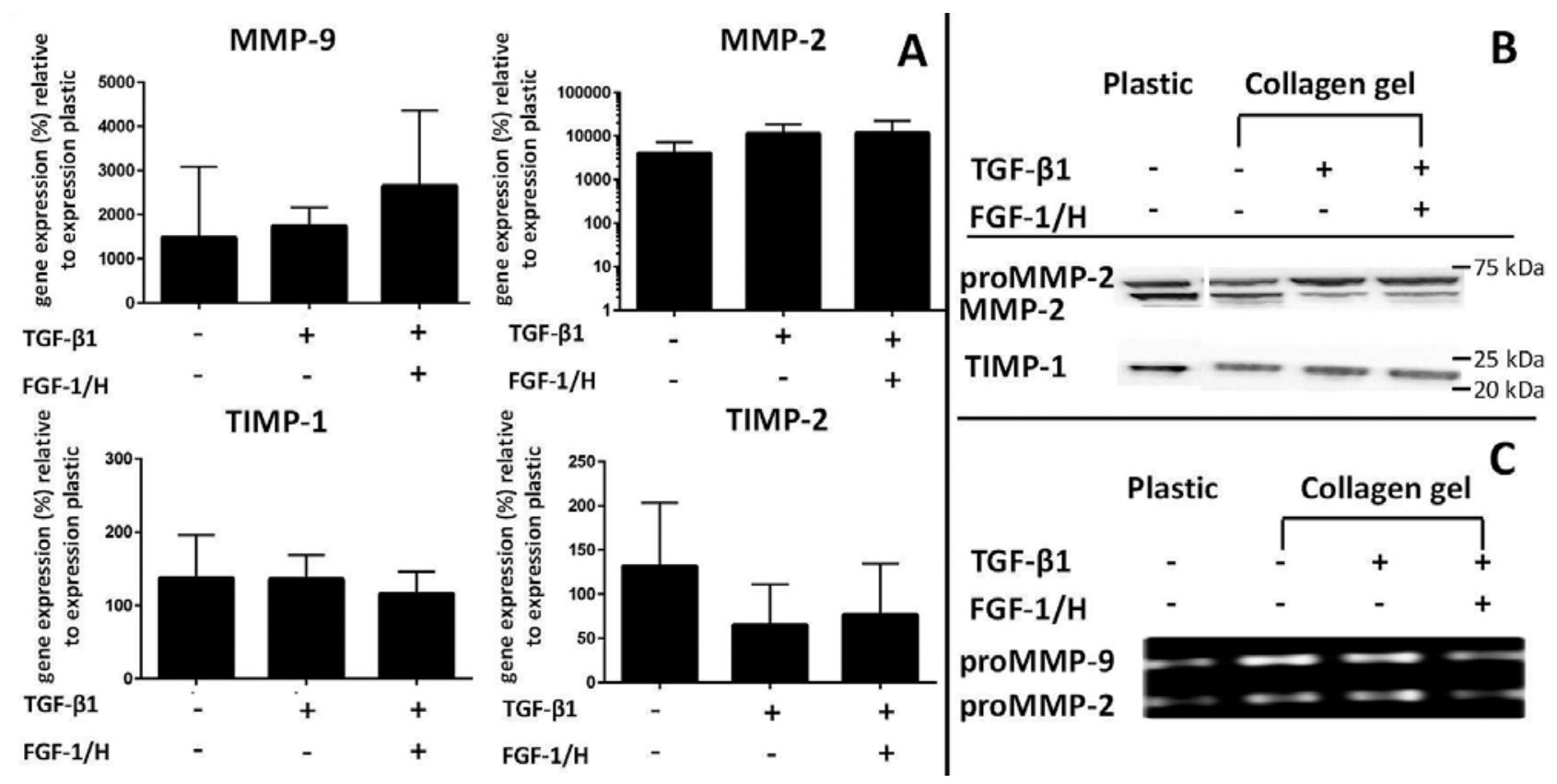

Fig. 4: Effect of FGF-1 on the expression of gelatinases and tissue inhibitors in the collagen gel. The cells were cultivated in the collagen gel, treated with TGF- $\beta 1$ for $24 \mathrm{~h}$, then for another $24 \mathrm{~h}$ with FGF-1/H in combination with TGF- $\beta 1$ or TGF- $\beta 1$ alone. TGF- $\beta 1$ stimulation or FGF-1/H treatment did not $t$ induce any significant changes in mRNA expression (cells seeded on plastic dishes are set as $100 \%$ ). Each bar represents mean \pm SD. Four independent experiments were performed. TGF- $\beta 1$ induced expression of pro-MMP-2, but not of the active form (B). Gelatinase activity was measured by a gelatin zymography (C).

proved by others (6) that the $\alpha$-SMA and FN positive cells are responsible for the overproduction of collagen type I in a fibrotic liver. Moreover, there is a correlation between expressions both proteins. Cellular FN consists of two splicing variants, namely ED-A and ED-B. It was shown that TGF- $\beta 1$ increases accumulation of the ED-A FN isoform (1). TGF- $\beta 1$ induction of ED-A FN is dependent on PI3kinase-AKT signalling (23). Our results on HCS-T6 showed that TGF- $\beta 1$ indeed induced its own mRNA expression and expression of $\alpha$-SMA, but had no effect on mRNA expression of procollagen I. Increase in fibronectin was detected in the TGF- $\beta 1$ stimulated cells at the protein level. The effect of FGF-1/H on HSC-T6 was ambiguous. It decreased the TGF- $\beta 1$ auto-induction, but conversely also potentiated the expression of $\alpha$-SMA mRNA. More importantly, FGF-1/H reduced $\alpha$-SMA and fibronectin at protein levels. Our data show that FGF-1 is sufficient to reduce the myofibroblastic differentiation, but the mechanism is not solely based on the downregulation of expression of the related genes. Our findings correspond with previous studies, suggesting that FGF-1 has an antifibrotic role: The myofibroblast phenotype reversal induced by FGF-1/H has been described in lung fibroblasts. Cells treated with FGF-1/H displayed increased apoptosis, decreased collagen production, and $\alpha$-SMA expression (25). FGF-1 also has the ability to revert EMT by inhibiting Smad2 phosphorylation through the MAPK/ERK pathway $(24,27)$.
Cells-to-matrix interaction could modify the phenotype of the myofibroblasts. Therefore, an understanding of this cooperation requires the use of the matrix-derived lattices. Various 2D or 3D matrices were studied in order to determine the influence of ECM on the myofibroblast activation. Collagen gels are used to mimic in vivo fibrotic conditions (10). It was published that TGF- $\beta 1$ stimulates a contraction of native collagen gels by HSC, these properties of HSC associated with an increase in $\alpha$-SMA content. This contraction was dependent on a HSC cell density in the collagen lattices (16). Others have reported that TGF- $\beta 1$-induced increase of $\alpha$-SMA content in a human gingival fibroblasts is dependent on the resistance of the substrate to deformation. Soft environment, represented by floating gels, did not increase mRNA for $\alpha$-SMA at all (2). The interaction of the collagen gel fibres with $\alpha 2 \beta 1$-integrin may be a restriction factor in stretch-induced $\alpha$-SMA and FN-EDA regulation. In our study we induced the myofibroblastic phenotype on both substrata - plastic dishes, which represent condition with high tensile strength, and the opposite collagen gel lattice, with a low tensile strength. We show that in HSC-T6 cells TGF- $\beta 1$ fails to induce the $\alpha$-SMA protein expression in the collagen gel. The TGF- $\beta 1$ stimulation appears to associate with an increase in FN-EDA. The FGF-1 treatment was able to markedly reduce this expression. We also provided the evidence that the $\alpha$-SMA expression is accompanied with the FN-EDA increase on the plastic as suggested by others 
$(14,33)$, but not in the collagen gel. Taken together, myofibroblasts are plastic cells that - if stimulated - can express some (but not all) profibrogenic markers. This expression is modulated by the three-dimensional environment. The FGF-1 treatment could possibly diminish some of these changes.

Proteolysis of ECM is a key player in the resolution of a liver fibrosis. The matrix degradation is achieved by the activity of MMPs, which consists of collagenases, gelatinases, stromelysins, and membrane type (MT)-MMPs. Various cytokines and growth factors, including TGF- $\beta 1$, control the balance between activators and inhibitors of proteinases. During an acute liver injury elevated levels of TGF- $\beta 1$, MMP-2, MMP-9, and TIMP-1 were found, suggesting their role in the early ECM remodelling (18). MMP-9 was found in scaring areas along with the activated HSC (11). TGF- $\beta 1$ stimulated expression of MMP-2 and TIMP-1 in vitro in dose dependent manner $(19,20)$. In our hands, stimulation of the cells with TGF- $\beta 1$ promoted MMP-2, MMP-9 and TIMP-1 expression and reduced the expression of TIMP-2, but no changes at the protein level were detected.

According to our previous results we presumed that FGF-1 might influence MMP and TIMP expression. A mild repression of secreted pro-MMP-2 and pro-MMP-9 was seen in culture media in the FGF-1/H treated cells. FGF-1/H presence reduced the TIMP-1 mRNA expression significantly. TIMP-1 is important in the inhibition of collagenase (MMP-1) and MMP-9, while TIMP-2 regulates the activity of MMP-2. Increase in the capacity for ECM turnover by reduction of protease inhibition is the goal of an anti-fibrotic therapy. Previous studies showed that 3D environment rich in type I collagen stimulates the ECM remodelling activities of HSC by induction of MMP-9 $(18,28)$. Collagen gel stimulates mRNA expression of MMP-2 as well as its activity in HSC-T6 cells. Mild decrease in secretion of pro-MMP-2 and pro-MMP-9 in the FGF-1/H treated cells was seen.

\section{Conclusion}

To address the effect of FGF-1 on myofibroblastic conversion of HSC-T6 cells, thecells were stimulated with TGF- $\beta 1$. The cells were cultivated in the monolayer cultures or on the collagen gels. FGF-1 significantly reduced levels of FN-EDA in the both environments, and significantly reduced levels of $\alpha$-SMA on plastic For this reason we conclude that FGF-1 could (by an unknown mechanism) antagonize the signals initiated by TGF- $\beta 1$; FGF- 1 is thus behaving as an antagonist of induction of myofibroblastic features in both plastic and in three-dimensional collagen matrices. FGF-1 represents a possible agent for pharmacological studies on the myofibroblastic activation during pathological events.

\section{Acknowledgements}

This work was supported by the project PRVOUK P37/01 and SVV-2016-260287.

\section{References}

1. Adapala RK, Thoppil RJ, Luther DJ, et al. TRPV4 channels mediate cardiac fibroblast differentiation by integrating mechanical and soluble signals. Journal of Molecular and Cellular Cardiology 2013; 54: 45-52.

2. Arora PD, Narani N, McCulloch CAG. The Compliance of Collagen Gels Regulates Transforming Growth Factor- $\beta$ Induction of $\alpha$-Smooth Muscle Actin in Fibroblasts. The American Journal of Pathology 1999; 154: 871-882.

3. Bataller R, Brenner DA. Liver fibrosis. Journal of Clinical Investigation 2005; 115 : 209-218.

4. Braunersreuther V, Viviani GL, Mach F, Montecucco F. Role of cytokines and chemokines in non-alcoholic fatty liver disease. World Journal of Gastroenterology 2012; 18: 727-35.

5. Broekelmann TJ, Limper AH, Colby TV, McDonald JA. Transforming growth factor beta 1 is present at sites of extracellular matrix gene expression in human pulmonary fibrosis. Proceedings of the National Academy of Sciences of the United States of America 1991; 88: 6642-6646.

6. Carpino G, Morini S, Corradini SG, et al. Alpha-SMA expression in hepatic stellate cells and quantitative analysis of hepatic fibrosis in cirrhosis and in recurrent chronic hepatitis after liver transplantation. Digestive and Liver Disease 2005; 37 : 349-356.

7. Derynck R, Muthusamy BP, Saeteurn KY. Signaling pathway cooperation in TGF$\beta$-induced epithelial-mesenchymal transition. Current Opinion in Cell Biology 2014; 31: 56-66.

8. Gressner AM, Weiskirchen R, Breitkopf K, Dooley S. Roles of TGF-beta in hepatic fibrosis. Frontiers Bioscience 2002; 7: 793-807.

9. Grinnell F, Petroll WM. Cell motility and mechanics in three-dimensional collagen matrices. Annual Review of Cell and Developmental Biology 2010; 26: 335-361.

10. Grinnell F. Fibroblast biology in three-dimensional collagen matrices. Trends in Cell Biology 2003; 13: 264-269.

11. Han YP. Matrix metalloproteinases, the pros and cons, in liver fibrosis. Journal of Gastroenterology and Hepatology 2006; 21(suppl 3): S88-S91.

12. Huang C, Day ML, Poronnik P, Pollock CA, Che XM. Inhibition of KCa3. 1 suppresses TGF- $\beta 1$ induced MCP-1 expression in human proximal tubular cells through Smad3, p38 and ERK1/2 signaling pathways. The International Journal of Biochemistry \& Cell Biology 2014; 47: 1-10.

13. Iredale JP, Thompson A, Henderson NC. Extracellular matrix degradation in liver fibrosis: Biochemistry and regulation. Biochimica et Biophysica Acta (BBA) Molecular Basis of Disease 2013; 1832: 876-83.

14. Jarnagin WR, Rockey DC, Koteliansky VE, Wang SS, Bissell DM. Expression of variant fibronectins in wound healing: cellular source and biological activity of the EIIIA segment in rat hepatic fibrogenesis. The Journal of Cell Biology 1994; 127: 2037-2048.

15. Jiroutova A, Peterova E, Bittnerova L, et al. Collagenolytic potential of rat liver myofibroblasts. Physiological Research 2013; 62: 15-25.

16. Kharbanda KK, Rogers DD, Wyatt TA, Sorrell MF, Tuma DJ. Transforming growth factor- $\beta$ induces contraction of activated hepatic stellate cells. Journal of Hepatology $2004 ; 41: 60-66$

17. Kim SJ, Ballock RT. Cellular and molecular biology of Transforming Growth Factors. In: Nosa M. Cellular and Molecular Biology of Bone 2014; 98: 122.

18. Knittel T, Mehde M, Kobold D, Saile B, Dinter C, Ramadori G. Expression patterns of matrix metalloproteinases and their inhibitors in parenchymal and non-parenchymal cells of rat liver: regulation by TNF- $\alpha$ and TGF- $\beta 1$. Journal of Hepatology 1999; 30:48-60.

19. Kwak HJ, Park MJ, Cho H, et al. Transforming growth factor- $\beta 1$ induces tissue inhibitor of metalloproteinase-1 expression via activation of extracellular signal-regulated kinase and Sp1 in human fibrosarcoma cells. Molecular Cancer Research 2006; 4: 209-220.

20. Mecha EO, Sui C, Omwandho CO, Tinneberg HR, Konrad L. Transforming Growth Factor Betas induce MMP-2 and MMP-9 Secretion via Smad-dependent Signaling in Human Endometrial and Endometriotic Cells. International Journal of Scientific Engineering and Technology 2015; 4: 567-72.

21. Mun JH, Kim YM, Kim BS, Kim J. H, Kim MB, Ko HC. Simvastatin inhibits transforming growth factor- $\beta 1$-induced expression of type I collagen, CTGF, and $\alpha$-SMA in keloid fibroblasts. Wound Repair and Regeneration 2014; 22: 125-33.

22. Peterová E, Mrkvicová A, Podmolíková L, Řezáčová M, Kanta J. The role of cytokines TGF-betal and FGF-1 in the expression of characteristic markers of rat liver myofibroblasts cultured in three-dimensional collagen gel. Physiological Research 2016; 65: 661-72.

23. Phanish MK, Heidebrecht F, Nabi ME, Shah, N, Niculescu-Duvaz I, Dockrell MEC. The regulation of TGF- $\beta 11$ induced fibronectin EDA exon alternative splicing in human renal proximal tubule epithelial cells. Journal of Cellular Physiology 2015; 230: 286-295.

24. Ramos C, Becerril C, Montaño M, et al. FGF-1 reverts epithelial-mesenchymal transition induced by TGF- $\beta 1$ through MAPK/ERK kinase pathway. American Journal of Physiology - Lung Cellular and Molecular Physiology 2010; 299: L222-L231. 
25. Ramos C, Montaño M, Becerril C, et al. Acidic fibroblast growth factor decreases $\alpha$-smooth muscle actin expression and induces apoptosis in human normal lung fibroblasts. American Journal of Physiology - Lung Cellular and Molecular Physiology 2006; 291: L871-L879.

26. Reeves HL, Friedman SL. Activation of hepatic stellate cells - a key issue in liver fibrosis. Frontiers Bioscience 2002; 7: 808-826.

27. Shimbori C, Bellaye PS, Xia J, et al. Fibroblast growth factor-1 attenuates TGF$\beta 1$-induced lung fibrosis. The Journal of Pathology 2016; 240: 197-210.

28. Takahara M, Naruse T, Takagi M, Orui H, Ogino, T. Matrix metalloproteinase- 9 expression, tartrate-resistant acid phosphatase activity, and DNA fragmentation in vascular and cellular invasion into cartilage preceding primary endochondral ossification in long bones. Journal of Orthopaedic Research 2004; 22 : $1050-57$.

29. Thakur S, Viswanadhapalli S, Kopp JB, et al. Activation of AMP-Activated Protein Kinase Prevents TGF- $\beta 1$-Induced Epithelial-Mesenchymal Transition and Myofibroblast Activation. The American Journal of Pathology 2015; 185: 2168-80.

30. Vogel S, Piantedosi R, Frank J, et al. An immortalized rat liver stellate cell line
(HSC-T6): a new cell model for the study of retinoid metabolism in vitro. Journal of Lipid Research 2000; 41: 882-893.

31. Wang Y, Lin C, Ren Q, Liu Y, Yang X. Astragaloside effect on TGF- $\beta 1$, SMAD2/3, and $\alpha$-SMA expression in the kidney tissues of diabetic KKAy mice. International Journal of Clinical and Experimental Pathology 2015; 8: 6828-34.

32. Wen FQ, Kohyama T, Sköld CM, et al. Glucocorticoids modulate TGF- $\beta$ production by human fetal lung fibroblasts. Inflammation 2003; 27: 9-19.

33. Wu J, Rnjak-Kovacina J, Du, Y, Funderburgh ML, Kaplan DL, Funderburgh JL. Corneal stromal bioequivalents secreted on patterned silk substrates. Biomaterials 2014; 35: 3744-55.

34. Herrmann J, Gressner AM, Weiskirchen R. Immortal hepatic stellate cell lines: useful tools to study hepatic stellate cell biology and function? Journal of Cellular and Molecular Medicine 2007; 11: 704-22.

Received: 05/10/2016

Accepted: 15/11/2016 